\title{
ANÁlISE MICROBIOLÓGICA DE ÁGUA DE NASCENTE E PROPRIEDADES RURAIS DO DISTRITO DE MUTÃS, GUANAMBI-BA
}

\author{
Marta Prates Nascimento ${ }^{1}$, Estefânia Prates Rodrigues $^{2 *}$, Paulo Túlio de Souza Silveira ${ }^{2}$, \\ Cinara Soares Pereira Cafieiro ${ }^{1}$, Paulo Fábio Neves de Souza ${ }^{1}$, Edvaldo Nascimento Costa ${ }^{3}$ \\ ${ }^{1}$ Instituto Federal Baiano - Campus Guanambi, Imbuí, 41720-052, Bahia, Brasil \\ ${ }^{2}$ Universidade Estadual de Campinas, Campinas, 13083-872, São Paulo, Brasil \\ ${ }^{3}$ Instituto Federal Baiano - Campus Governados Mangabeira, Imbuí, 41720-052, Bahia, Brasil
}

Autor para correspondência: Estefânia Prates Rodrigues; e-mail: tefaprates@ hotmail.com

Recebido: 21/08/2020, Aceito: 08/11/2020

\section{Resumo}

Neste estudo, objetivou-se avaliar a qualidade microbiológica da água de nascente, reservatório e de residências da zona rural do distrito de Mutãs em Guanambi-BA, quanto à presença de coliformes totais, termotolerantes e contagem em placa de bactérias mesófilas heterotróficas. Foram coletadas dez amostras de água em cinco pontos distintos: uma nascente, um reservatório e outras três residências. As análises microbiológicas foram realizadas de acordo com os procedimentos metodológicos descritos no manual Standard Methods for the Examination of Waterand Wastewater, publicação da American Public Health Association (APHA), cujas técnicas adotadas quantificam os coliformes e as bactérias heterotróficas na água. Por meio de análises realizadas, foi possível avaliar a presença ou ausência de bactérias do grupo coliforme; dos 5 pontos analisados, o primeiro (P1) não apresentou contaminação de coliformes nas duas coletas, sendo este a amostra que representa a nascente. Porém, nos demais pontos (os reservatórios P2, P3, P4 e P5), os resultados variaram, com presença e ausência nas coletas. Para bactéria heterotrófica, pode-se verificar que, das dez amostras analisadas, $90 \%$ obtiveram resultados aceitáveis para o consumo humano e $10 \%$ apresentaram contagens acima dos permitidos pela legislação vigente. Assim, fazem-se necessários cuidados com a água e/ou reservatório para a disponibilização de uma água de qualidade para a população.

Palavras-chave: Água potável, coliformes termotolerantes, coliformes totais, bactérias mesófilas

\section{MICROBIOLOGICAL ANALYSIS OF SOURCE WATER AND RURAL PROPERTIES OF THE MUTÃS DISTRICT, GUANAMBI-BA}

\begin{abstract}
The main objective of this study was to evaluate the microbiological quality of spring water, reservoir and residences in the rural area of the district of Mutãs in Guanambi - BA, regarding the presence of total coliforms, thermotolerant and plate count of heterotrophic mesophilic bacteria. Ten water samples were collected at five different points: a spring, a reservoir and three other residences. Microbiological analyzes were carried out according to the methodological procedures described in the Standard Methods for the Examination of Water and Wastewater, published by the American Public Health Association (APHA), whose techniques quantify coliforms and heterotrophic bacteria in water. Through analyses carried out, it was possible to evaluate the presence or absence of bacteria of the coliform group; of the 5 points analyzed, the first (P1) did not present coliform contamination in the two collections, this being the sample that represents the source. However, in the other points (reservoirs P2, P3, P4 and P5), the results varied, with presence and absence in the collections. For heterotrophic bacteria, it can be verified that, of the ten samples analyzed, 90\% obtained acceptable results for human consumption and $10 \%$ presented counts higher than those allowed by current legislation. Thus, water and/or reservoir care is necessary to provide quality water to the population.
\end{abstract}

Keywords: Drinking water, thermotolerant coliforms, total coliforms, mesophilic bacteria 


\section{Introdução}

A água é essencial à sobrevivência da humanidade e indispensável para a produção de alimentos e outras atividades com fins econômicos. Por isso, os humanos e toda a biodiversidade dependem deste recurso natural (SILVA, 2011).

A água de consumo humano é o principal veículo de transmissão de patógenos capazes de causar infecções gastrointestinais, sendo vital o seu controle microbiológico. A ingestão de alimentos contaminados com microrganismos provenientes de água de má qualidade, utilizada em seu preparo, pode tornar-se um problema para aqueles que fazem o consumo e, consequentemente, para os órgãos de saúde pública, uma vez que os gastos com o tratamento de doenças por ingestão de alimentos contaminados por bactérias, principalmente do grupo coliforme, são elevados (SOUSA, 2006).

A característica necessária à água distribuída para consumo humano é a potabilidade, ou seja, deve ser limpa e estar livre de qualquer contaminação de origem microbiológica, química, física ou radioativa, não devendo, em hipótese alguma, oferecer riscos à saúde humana (BRASIL, 2004). Para que a água seja considerada potável do ponto de vista microbiológico, tem que estar livre de bactérias indicadoras de contaminação fecal e não deve conter microorganismos patogênicos. São tradicionalmente aceitos como indicadores de contaminação fecal um grupo de bactérias denominadas coliformes (BRASIL, 2006).

De modo geral, a água está ligada à sobrevivência da natureza, possibilitando melhorias nas condições econômicas, sociais e comunitárias. É fundamental que a água, para consumo humano, apresente condições físicas, químicas e microbiológicas dentro dos limites estabelecidos por legislação vigente à sua utilização. $\mathrm{O}$ melhor método de assegurar água adequada ao consumo humano consiste em formas de proteção, evitando a iminência de contaminações e a exposição das pessoas a riscos de doenças (ZANCUL, 2006).

Ainda existem os riscos de surtos de doenças de veiculação hídrica em comunidades consumidoras de água não tratada, principalmente em função de possível contaminação bacteriana de águas que por vezes são captadas diretamente em nascentes, poços ou outras fontes que não são vedados de forma adequada e têm fontes de contaminação próximas (MATTOS; SILVA, 2002).

Nas nascentes, devido à falta de proteção adequada no local do afloramento ou em suas proximidades, a água pode ser facilmente contaminada, não podendo, assim, ser consumida. Portanto, as áreas devem ser devidamente cercadas, impedindo a entrada de contaminantes que põem em risco a sua qualidade (LEAL, 2012).

De acordo com Vaz (2004), preservar e recuperar as nascentes d'água se constitui como ações para continuidade da vida em longo prazo, e não apenas como atitudes em consonância com a legislação ou para a permanência da prática de atividades humanas.

De acordo com Bromberg (2009), falhas na proteção e no tratamento efetivo expõem a comunidade a riscos de doenças intestinais e a outras doenças infecciosas. A preservação da qualidade das águas é uma necessidade universal que exige séria atenção por parte das autoridades sanitárias, sendo indispensável a realização de exames bacteriológicos rotineiros para a avaliação da qualidade da água a ser consumida (GUEDES et al., 2004).

Assim, o monitoramento da qualidade da água destinada ao consumo humano da população rural torna-se, portanto, imprescindível, principalmente das águas que abastecem vilas e comunidades rurais, as quais possuem maior concentração de pessoas. Isso previne o aparecimento de várias doenças no homem, auxilia o diagnóstico das principais formas de contaminação e indica um conjunto de práticas de manejo dos recursos naturais que possibilitem o controle da poluição e aumento da qualidade de vida dos usuários dessa água (GONÇALVES et al., 2005).

Diante do exposto, objetivou-se avaliar a qualidade da água de nascente, reservatório e residências da zona rural do distrito de Mutãs, Guanambi - Bahia, por meio da contagem de coliformes totais, termotolerantes e bactérias aeróbias mesófilas.

\section{Material e Métodos}

\section{Coleta e análise}

As coletas das amostras foram realizadas em uma nascente, um reservatório e três residências no distrito de Mutãs, zona rural de Guanambi, no estado da Bahia. A região onde é localizada a nascente reside uma população com cerca de 200 habitantes que utilizam a água para o consumo.

Esta água não é submetida a tratamento e atende a todos os moradores locais, diariamente, e o seu fornecimento é de responsabilidade dos próprios moradores da região, sem nenhum vínculo com órgãos públicos. $\mathrm{O}$ ponto $\mathrm{P} 1$ é a nascente. $\mathrm{O}$ ponto $\mathrm{P} 2$ é o reservatório. As residências são os pontos P3, P4 e P5. As coletas das residências foram determinadas de forma aleatória.

As coletas das amostras foram realizadas nos dias 23 e 25 de outubro de 2016, cujas amostras foram depositadas diretamente nos frascos de coleta. Em seguida, foram acondicionados em caixa térmica com gelo e mantidos em refrigeração, sendo, por fim, 
encaminhado para o Laboratório de Microbiologia do Instituto Federal de Educação, Ciência e Tecnologia Baiano, Campus Guanambi.

As análises para a determinação de coliformes totais, termotolerantes e contagem em placa de bactérias heterotróficas aeróbias mesófilas foram realizadas em duplicata com duas repetições.

\section{Procedimentos para coleta}

As coletas foram realizadas manualmente com os devidos cuidados higiênicos. Primeiramente, foi feita a higienização das mãos, logo após, com todos os cuidados de assepsia, fez-se a higienização na tampa do frasco com álcool. Na sequência, retirou-se a tampa e, com uma das mãos, segurou-se o frasco pela base, mergulhando-o rapidamente com a boca para baixo, a cerca de 20 a $30 \mathrm{~cm}$ abaixo da superfície da água, para evitar a introdução de contaminantes superficiais. Direcionou-se o frasco de modo que a boca permanecesse em sentido contrário à corrente, inclinando-o lentamente para cima para permitir a saída do ar e consequente o enchimento. Depois de retirado o frasco da água, uma pequena porção da amostra foi desprezada, deixando um espaço vazio suficiente para permitir uma boa homogeneização da amostra antes do início da análise. Depois da coleta da amostra, fechouse o frasco e identificou-o com o nome da amostra correspondente ao ponto da coleta. Em seguida, o frasco foi colocado na caixa térmica com gelo, lacrado e identificado para ser conduzido ao laboratório.

Nas residências, a coleta ocorreu de forma manual. Primeiramente, a higienização das mãos com água, sabão e álcool; em seguida, efetuou-se a higienização da torneira da residência com algodão embebido em álcool $70 \%$. Depois, abriu-se novamente a torneira deixando escorrer a água durante 1 ou 2 minutos; fechou-se e desinfetou-se a torneira. Após esse processo, abriu-se outra vez, deixando escorrer por mais 2 ou 3 minutos. Em seguida, coletou-se a amostra da água, enchendo o frasco parcialmente. Depois da coleta, tampou-se o frasco e identificou-o com o nome da amostra, correspondente ao ponto da coleta. Colocou-se o frasco na caixa térmica com gelo, lacrando-a e identificando-a para ser levada ao laboratório (BRASIL, 2006).

\section{Análises microbiológicas}

As análises microbiológicas foram realizadas de acordo com os procedimentos metodológicos descritos no Manual Prático de Análise de Água (BRASIL, 2004). Foi realizada em todas as amostras a análise para coliformes totais e termotolerantes pela técnica de número mais provável $(\mathrm{NMP} / \mathrm{mL})$ e contagem em placa de bactérias heterotróficas aeróbias mesófilas (UFC/mL).

\section{Coliformes totais e termotolerantes}

Para realização do teste presuntivo, utilizou-se uma bateria com nove tubos de ensaio distribuídos de três em três. Nos primeiros três tubos, contendo caldo lactosado de concentração dupla, foi inoculada, com auxílio de uma pipeta esterilizada, $10 \mathrm{~mL}$ da amostra da água a ser examinada, em cada tubo sendo a diluição 1:1. Nos seis tubos restantes contendo caldo lactosado de concentração simples, foram inoculados nos três primeiros $1 \mathrm{~mL}$ da amostra sendo a diluição 1:10 e nos 3 últimos $0,1 \mathrm{~mL}$ da amostra em cada tubo sendo a diluição 1:100. Em seguida, foram homogeneizados e incubados a $35^{\circ} \mathrm{C}$ durante 24 horas. Para detecção da presença de coliformes, os tubos com formação de gás realizaram o teste confirmativo.

Para a etapa do teste confirmativo, com os tubos do teste presuntivo que deram positivos nas 3 diluições 1:1; $1: 10 ; 1: 100$, transferiu-se uma alçada carregada dos tubos caldo lauryl sulfato triptose (LST) para os tubos contendo caldo verde brilhante bile $2 \%$ (VB), analisando a contagem dos coliformes totais. Em seguida, os tubos foram incubados durante 24 horas a $35^{\circ} \mathrm{C}$.

Para a verificação de coliformes termotolerantes, com os tubos de caldo lauryl sulfato triptose (LST) que deram positivo com formação de gás, inocularam-se uma alçada em tubos de caldo Escherichia Coli (EC). Posteriormente, foram incubados em temperatura de $45^{\circ} \mathrm{C}$ durante 24 a 48 horas. Este ensaio foi realizado simultaneamente com o teste confirmativo para coliformes totais e deve ser feito sempre que for realizado teste confirmativo para coliformes totais.

\section{Contagem em placa de bactérias heterotróficas aeróbias mesófilas ( $U F C / m L)$}

Das diluições $10^{-1}, 10^{-2}$ e $10^{-3}$, com uma pipeta estéril transferiu-se $0,1 \mathrm{~mL}$ de cada diluição da amostra para placas de Petri, estéreis pelo método spread plate. $\mathrm{Na}$ sequência, as placas foram incubadas em posição invertida a $35^{\circ} \mathrm{C}$ durante 48 horas. No final do período de incubação, foi feita a contagem das colônias com o auxílio de um contador de colônias.

\section{Resultados e Discussão}

\section{Determinação de bactérias do grupo coliforme}

Através das análises realizadas foi avaliada a presença ou ausência de bactérias do grupo coliforme, os resultados de Número Mais Provável por mL $\mathrm{NMP} / \mathrm{mL}$ - para coliformes totais e termotolerantes encontrados nas amostras analisadas estão representados na Tabela 1. 
Tabela 1 - Determinação de bactérias do grupo coliformes por $\mathrm{NMP} / \mathrm{mL}$.

\begin{tabular}{|c|c|c|c|c|}
\hline \multirow[t]{2}{*}{$\begin{array}{c}\text { Amostrage } \\
\mathrm{m}\end{array}$} & \multicolumn{2}{|c|}{$\begin{array}{l}\text { Coliformes Totais } \\
\text { (NMP/100 mL) }\end{array}$} & \multicolumn{2}{|c|}{$\begin{array}{c}\text { Coliformes } \\
\text { Termotolerantes } \\
(\mathrm{NMP} / 100 \mathrm{~mL})\end{array}$} \\
\hline & $1^{\circ}$ coleta & $2^{\circ}$ coleta & $1^{\circ}$ coleta & $2^{\circ}$ coleta \\
\hline $\mathrm{P} 1$ & Ausência & Ausência & Ausência & Ausência \\
\hline $\mathrm{P} 2$ & Ausência & Ausência & Ausência & Ausência \\
\hline P3 & Ausência & Ausência & Ausência & Ausência \\
\hline P4 & Ausência & Ausência & Ausência & Ausência \\
\hline P5 & Ausência & Ausência & Ausência & Ausência \\
\hline
\end{tabular}

NMP: Número Mais Provável. P1: Nascente. P2: Reservatório. P3: Residência. P4: Residência. P5: Residência. Fonte: Dados da pesquisa (2017).

Segundo a Portaria n. 05/2017 do Ministério da Saúde, a água para o consumo humano deve apresentar ausência de coliformes totais e termotolerantes em amostra de $100 \mathrm{~mL}$ de água (BRASIL, 2004).

A amostra P1 (nascente) não apresentou contaminação de coliformes nas duas coletas, apresentando-se, assim, dentro do parâmetro exigido pela legislação, que determina a necessidade de apresentar ausência de coliformes totais e termotolerantes em amostra de $100 \mathrm{~mL}$ de água. Portanto, a água é permitida para o consumo humano no P1 (BRASIL, 2017).

Em relação à amostra analisada no ponto $\mathrm{P} 2$, o reservatório próximo a nascente, houve contaminação na segunda coleta, porém não apresentando contaminação na primeira. Pode-se observar que a contaminação presente houve uma possível falha de higienização, visto que a coleta da amostra foi realizada dois dias após a limpeza do reservatório, diferente da primeira, realizada no mesmo dia.

No que tange às amostras P3 e P4, apresentaram-se contaminação apenas na segunda coleta, diferente da primeira, que não apresentou. Desse modo, a água encontrava-se imprópria para o consumo.

A amostra P5, a última residência, apresentou contaminação apenas na primeira coleta, contudo, na segunda coleta não apresentou nenhuma contaminação. No entanto, pode-se analisar que a contaminação da primeira coleta talvez possa ter ocorrido, devido à falta de higienização do reservatório, pois encontrava-se há quatro meses sem cuidados. Segundo o proprietário, após ter realizado a primeira coleta, o reservatório foi higienizado, portanto, para a segunda coleta, o reservatório estava em estado apropriado. Pode-se observar que a contaminação não é só por conta do tratamento da água, e, sim, por falta de higienização nas tubulações e torneiras das residências e reservatórios.

Resultados semelhantes foram encontrados por Lunardão (2008), na cidade de Lins no estado de São Paulo, onde foram coletadas amostras de água não tratada provenientes de 140 residências, e os resultados indicaram a presença de coliformes em 67,86\% (95 residências). Em 32,14\%, houve ausência deste grupo de microrganismo. Estes resultados indicam que há falta de manutenção nos reservatórios, pois a presença de bactérias do grupo coliforme é um indicativo, sendo que no ponto de entrada da água nestas residências indicaram ausência destes microrganismos, confirmando se tratar de problemas referentes ao sistema interno.

Assim, analisando os resultados positivos e negativos para coliformes totais e termotolerantes, apenas a nascente apresenta qualidade de água em condições de potabilidade adequadas para o consumo humano. Os resultados do reservatório e das três residências mostraram variações de um para o outro, apresentando contaminações. Porém, não indicam que há problema com a qualidade da água que é fornecida e, sim, supostamente, pela falha dos proprietários, principalmente em relação à higienização de seus reservatórios. Por isso, uma limpeza periódica nos reservatórios de água e seu bom fechamento podem impedir que haja contaminação e desenvolvimento de microrganismos.

Para evitar a contaminação, os proprietários devem fazer sempre a higienização sanitária nos canos, nos reservatórios e até mesmo nas torneiras na parte interna das propriedades.

Conforme a Figura 1, é possível observar a variação dos resultados por Número Mais Provável (NMP/100 $\mathrm{mL}$ ) em porcentagem quanto à ausência de coliformes totais e termotolerantes nas amostras, baseado na primeira e segunda coleta. Como observa-se na Figura 1, $80 \%$ das amostras apresentaram ausência para coliformes totais e termotolerantes na primeira coleta, enquanto a segunda somente $40 \%$.

Em comparação com a porcentagem da primeira e segunda coleta de ausência de coliformes, mais resultados foram observados nas amostras de água destinada ao consumo humano em propriedades rurais no estado de São Paulo, onde 86,7\% estavam fora dos padrões microbiológicos de potabilidade para coliformes (AMARAL et al., 2003). Considerando os resultados obtidos nas contagens de coliformes, comparados com o padrão exigido pela legislação vigente, pode-se afirmar que as amostras avaliadas apresentaram imprópria para o consumo. 


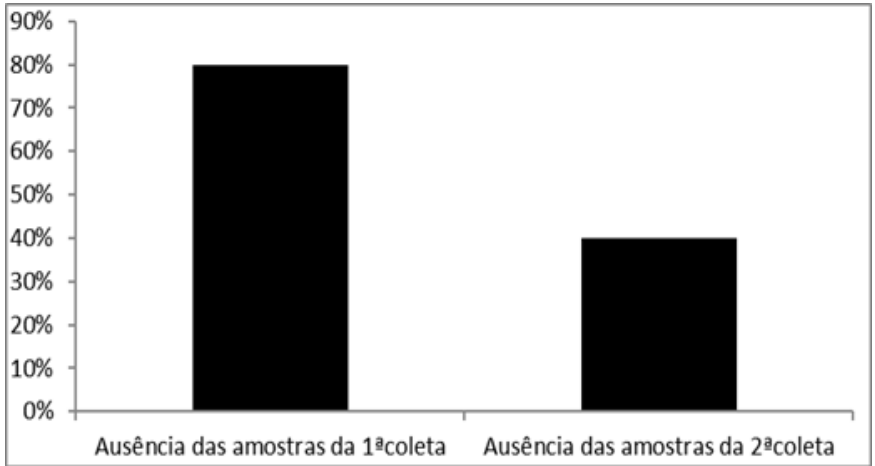

Figura 1 - Resultados em porcentagem de amostras de água com ausência de coliformes Totais e termotolerantes. Fonte: Dados da Pesquisa (2017).

Determinação para a contagem padrão em placa de bactérias heterotróficas aeróbias mesófilas ( $\mathrm{UFC} / \mathrm{mL})$

De acordo com a Portaria n. 05/2017 do Ministério da Saúde, a contagem padrão das bactérias heterotróficas aeróbias mesófilas ( $\mathrm{UFC} / \mathrm{mL}$ ) não deve exceder 500 unidades formadoras de colônias por 1 mililitro de amostra (500 UFC/mL) (BRASIL, 2004).

Sabioni e Silva (2006) afirmam que as bactérias heterotróficas são encontradas naturalmente na água e enfatizam a importância do controle de sua densidade, pois em números elevados podem causar riscos à saúde do consumidor, uma vez que podem atuar como patógenos secundários.

A Contagem Padrão em Placa de bactérias heterotróficas aeróbias mesófilas (UFC/mL) analisada nas duas coletas é apresentada na Tabela 2.

Tabela 2 - Contagem Padrão em Placa de bactérias heterotróficas aeróbias mesófilas (UFC/mL)

\begin{tabular}{ccc}
\hline \multirow{2}{*}{ Amostragem } & \multicolumn{2}{c}{$\begin{array}{c}\text { Bactérias Mesófilas Heterotróficas } \\
(\mathrm{UFC} / \mathrm{mL})\end{array}$} \\
\cline { 2 - 3 } & $1^{\circ}$ coleta & $2^{\circ}$ coleta \\
\hline P1 & Ausente & Ausente \\
P2 & Ausente & Ausente \\
P3 & Ausente & Ausente \\
P4 & Ausente & Ausente \\
P5 & Incontável & Ausente
\end{tabular}

Notas: UFC: Unidades Formadoras de Colônias. P1: Nascente. P2: Reservatório. P3: Residência. P4: Residência. P5: Residência. Fonte: Dados da pesquisa (2017).

Porém, a primeira coleta apresentou resultados inferiores à segunda, isso porque apenas a amostra P5 mostrou-se fora dos padrões microbiológicos para bactérias aeróbias mesófilas em relação à qualidade da água para consumo humano, apresentando número de colônia superior ao permitido, enquanto nas amostras P1, P2, P3, e P4 foram ausentes.

Já na segunda coleta, na amostra P5, os resultados foram satisfatórios. Diferentemente da primeira, nesta coleta, não ocorreu contaminação, posto que foi realizada a limpeza no reservatório um dia antes da coleta. Os pontos analisados apresentaram todos ausentes para bactérias heterotróficas.

Nesta perspectiva, faz-se contundente citar uma pesquisa semelhante realizada por Guerra et al. (2006), na qual foram analisadas 413 amostras de água potável do sistema principal e secundário em Bandeirantes - PR. Os resultados mostraram que somente $0,24 \%$ apresentou-se acima do nível máximo recomendado.

Silva e Araújo (2003) verificaram resultados diferentes, analisando a qualidade da água do manancial subterrâneo em áreas urbanas em Feira de Santana, na Bahia. Os pesquisadores observaram um resultado expressivo pois das 119 amostras analisadas, 85 (71,4\%) obtiveram mais de $500 \mathrm{UFC} / \mathrm{mL}$.

A importância da determinação da densidade de bactérias tem em vista um aumento na população bacteriana, podendo comprometer a detecção de bactérias do grupo coliformes. Apesar da maioria das bactérias heterotróficas não ser patogênica, pode-se representar riscos à saúde, como também deteriorar a qualidade da água, provocando o aparecimento de odores e sabores desagradáveis (BRASIL, 2004).

Pode-se verificar na Figura 2 que, das 5 amostras analisadas na primeira coleta, $80 \%$ apresentaram ausência de bactérias heterotróficas. Este resultado foi afetado por falta de informações, decorrentes da manutenção, limpeza e higienização do reservatório, visto que na segunda coleta todas apresentaram resultados dentro do limite permitido de $500 \mathrm{UFC} / \mathrm{ml}$, com uma porcentagem de $100 \%$.

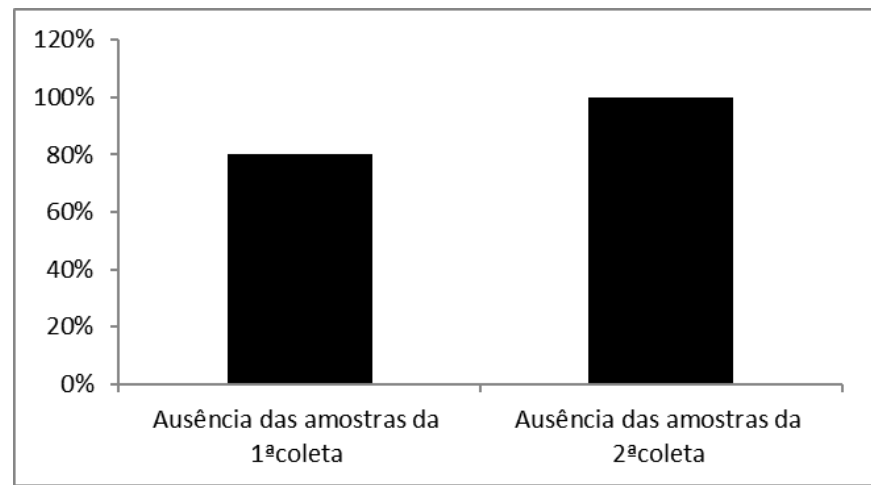

Figura 2 - Resultado em porcentagem de ausência obtida nas coletas das análises da água por contagem de bactérias heterotróficas aeróbias mesófilas na água. Fonte: Dados da Pesquisa (2017). 
Resultados semelhantes a esses foram encontrados também por Gomes et al. (2005), ao avaliarem amostras de água de bebedouros obtidas de uma Instituição Federal de Ensino Superior (IFES) do Sul de Minas Gerais, nos quais verificaram que $75 \%$ das amostras estavam satisfatórias para o consumo humano quanto ao número de bactérias heterotróficas, sendo que o restante ultrapassou o limite permitido de $500 \mathrm{UFC} / \mathrm{mL}$.

Para Silva e Araújo (2003), o consumo de água que atenda os padrões de potabilidade constitui uma ação de política pública de prevenção de doenças e mortalidades, as águas que não atendam este padrão recomendável precisam ser evitadas, através de informações e promoções de políticas públicas que garantam o acesso à água adequada ao consumo humano.

É de grande importância dos poderes públicos federais, estaduais e municipais, secretarias de educação e meio ambiente como também a sociedade civil organizada, divulgar informações e esclarecimentos à população através de campanhas, palestras comunitárias e escolares, a respeito da preservação e uso de água de poço, bem como os riscos e perigos atuais e iminentes (VASCONCELOS, 2006).

\section{Considerações finais}

Em relação aos parâmetros microbiológicos por meio de avaliação de bactérias heterotróficas aeróbias mesófilas presentes na água, das 10 amostras analisadas, 9 (90\%) estão em conformidade com os parâmetros aceitos para consumo humano, de acordo com a legislação vigente, apenas $1(10 \%)$ da primeira coleta apresentou contaminação.

Para coliformes totais e termotolerantes, pode-se observar que apresentaram contaminação nas residências e no reservatório, ao contrário da nascente, que indicou a presença de água de boa qualidade.

Percebe-se com os resultados uma situação de risco nas propriedades, em decorrência das contaminações analisadas. Deste modo, para consumir uma água de boa qualidade é preciso tratar de forma correta os reservatórios, necessitando de tratamento direto na água, para garantir, assim, água potável dentro dos padrões exigidos pela legislação e evitando contaminações e risco de doenças.

\section{Referências}

AMARAL, L. A.; FILHO, A. N.; JUNIOR, O. D. R.; FERREIRA, F. L. A.; BARROSET, L. S. S. Água de consumo humano como fator de risco à saúde em propriedades rurais. Revista Saúde Pública, v. 37, n. 4, 2003.
BRASIL. Fundação Nacional da Saúde. Ministério da Saúde. Manual prático de análise de água. Brasília: FUNASA, 2004.

Fundação Nacional de Saúde. Manual prático de análise de água. 2. ed. Brasília: FUNASA, 2006.

Portaria n. 5, de 03 de outubro de 2017. Legislação para águas de consumo humano. Diário Oficial da República Federativa do Brasil. Brasília, DF, 03 de outubro de 2017.

BROMBERG, M. Seguro água potável: Microbiais Standards garantir a qualidade da água para os consumidores. 2009. Disponível em: <http://www.hermes.ecn.purdue.edu/ cgi/convqtes?/ru-7.il.ascii>. Acesso em: 03 jul. 2016.

GOMES, P. C. F. L.; JÚLIA, C. J.; VEIGA, M. M.; MORAIS, S. M. OLIVEIRA. Análise físico-química e microbiológica da água de bebedouros de uma IFES do sul de Minas Gerais. Revista Higiene Alimentar. v. 19, n. 133 , p. 63-65, 2005.

GONÇALVES, C. S.; RHEINHEIMER, D. D. S.; PELLEGRINI, J. B. R., KIST, S. L. Qualidade da água numa microbacia hidrográfica de cabeceira situada em região produtora de fumo. Revista Brasileira de Engenharia Agrícola e Ambiental. Campina Grande, v. 9, n. 3, p. 391-399, 2005.

GUEDES, Z. B. L.; FERREIRA, O. H.; BANDEIRA, B. N. P.; NETO, S.; SILVEIRA, J. W.; CAMPELO, L. A. E.; Controle Sanitário da água consumida nas unidades de saúde do município de Fortaleza, CE. Revista Higiene Alimentar, v. 18, n. 125, p. 28-31, 2004.

GUERRA, N. M. M.; OTENIO, M. H.; SILVA, M. E. Z.; GUILERMETTI, M.; NAKAMURA, C.V.; NAKAMURA, T.U.; FILHO, B.P.D. Ocorrência de Pseudomonas aeruginosa em água potável. Revista Acta Scientiarum Biological Sciences, v. 18, n. 1, p. 13-18, 2006.

LEAL, J. T. C. P. Água para consumo na propriedade rural. Belo Horizonte: EMATER-MG. 18 p. 1. Água. 2. Saneamento. I. EMATER-MG. II. 2012.

LUNARDÃO, G. Análise microbiológica da água procedente de reservatórios residenciais do município de Lins - SP. Lins - SP, 2008.

MATTOS, M. L. T.; SILVA, M. Controle da qualidade microbiológica das águas de consumo na microbacia 
hidrográfica Arroio Passo do Pilão. Ministério da Agricultura, Pecuária e Abastecimento. Comunicado Técnico n. 61. 2002.

ROGER P. MORMUL, R. P.; KWIATKOWSKI, A.; ZERBINI, D. L. N.; ANDREIA A. DE FREITAS, A. A.; ALMEIDA, A. C. G. Avaliação da Qualidade da água em nascentes da favela de São Francisco de Campo Mourão/PR. Sábios: Revista Saúde e Biologia. Campo Mourão, v. 1, n.1, 2006.

SABIONI, J. G.; SILVA, I. T. Qualidade microbiológica de águas minerais comercializadas em Ouro Preto, MG. Revista Higiene Alimentar, v. 20, n. 143, p. 72-78, ago. 2006.

SILVA, M. A. D. Direito internacional à água. Universidade Autónoma de Lisboa. 2011.

SILVA, R. C. A.; ARAÚJO, T. M. Qualidade da água do manancial subterrâneo em áreas urbanas de Feira de Santana (BA). Ciência \& Saúde Coletiva, v. 8, n. 4, p. 1019-1028, 2003.

SOUSA, C. P. Segurança alimentar e doenças veiculadas por alimentos: utilização do grupo coliforme como um dos indicadores de qualidade de alimento. Revista Atenção Primária à Saúde, v. 9, n. 1, p. 8388, 2006.

VASCONCELOS, T. A. Estudo Físico-Químico e Microbiológico de Águas de poços Tubulares da Cidade de Manaus. 2006. 118 f. Dissertação (Mestrado em Geologia Ambiental) - Universidade Federal do Amazonas, 2006.

VAZ, D. Preservação e conservação das nascentes. Curso de engenharia ambiental. UNICALDAS, 2004.

ZANCUL, M. S. Água e saúde. Revista Eletrônica de Ciências. 2006. Disponível em: <http://cdcc.sc.usp.br/ciencia/artigos/art32/atualida des>. Acesso em: março de 2016. 